\title{
What Makes University Students Happy?
}

Esa Mangeloja and Tatu Hirvonen 1

\begin{abstract}
Happiness studies are a growing research area in economics. In this study we focus on the determinants of subjective well-being of a particular sub-population, university students. Different happiness determinants are considered and tested empirically using survey data from Finland. An ordered probit model is applied. We compare the results with those of a similar study conducted among university students in Australia. The findings reveal that the most important influences on students' levels of satisfaction are social relationships, resources and the educational environment, personal goal achieving and extracurricular activities.
\end{abstract}

\section{Introduction}

Happiness is a growing research area in economics. According to a recent review by Kahneman and Krueger (2006) economic papers analysing data on self-reported life satisfaction or happiness have risen from a mere four in the period 1991-95 to more than 100 papers during 2001-05. Other recent reviews include Layard's book Happiness - Lessons from a New Science (2005), Happiness in Economics (2002) edited by Easterlin, and Frey's and Stutzer's book Happiness and Economics (2002). During the past ten years economists have studied happiness in relation to earnings, economic growth, income inequality, inflation, institutions, human development index, consumption, globalisation and unemployment.

Several papers have also looked into the relationship between education and happiness. If we argue that the fundamental philosophy behind economics is the pursuit of human happiness, then we should study it directly (e.g. Layard, 2005) and, although we cannot define happiness (after all, happiness means different things to different people), we can nevertheless ask people whether they feel happy or not (e.g. Frey and Stutzer, 2002). Although the general view of age as an influence on happiness is considered close to nil (e.g. Frey and Stutzer, 2002), age was also found 
to be an important explanatory variable by Hirvonen and Mangeloja (2005). Their results indicated that older Finns seem to be less happy than younger ones. This result seems even more interesting when compared to the study at hand, as the bulk of the respondents (over $95 \%$ out of 244 ) were between 18 and 28 -year-old Finns.

Another point of reference with respect to age, and youth in particular, is the study by Blanchflower and Oswald (1997). They show that fears of unhappiness among young people in the US and Europe (Finland not included) have been unfounded. In fact, it would seem that happiness among young people rose between the 1970s and 1990s (the time period covered by the data). One explanation that they offered for this increase was education. Their data show that Europeans with higher education (staying on school after 18) and under age 30 benefited the most from the subsequent 'growth of happiness'.

Although in the earlier study by Hirvonen and Mangeloja (2005) level of education was not found to be significant in the Finnish case, it was highly significant when the results of all the countries were combined (Finland, Sweden, Norway, the US, West-Germany, Spain and Mexico). However, the effect was found to be negative. Clark and Oswald (1996) came to the same conclusion in their study. They found that the higher educated seemed to derive less satisfaction from work, which was: 'counter to what neoclassical economic theory might lead one to expect'. Their explanation is that 'education raises aspiration targets'. So, are we to expect university students to be happy or unhappy?

According to the reviews of education and happiness by Diener et al. (1999) and Argyle (2002), there seems to be 'small (.12-.06) but significant (positive) correlations' between education and happiness 'assessed by number of years of education and or the level of highest qualification acquired'. The effect of education on happiness comes from work (better and more satisfying jobs), from occupational status and, finally, from income. In short, studies show that education may increase happiness, but only indirectly and only after receiving it. So, in a way happiness is 'a return from schooling' (see: e.g. Hartog and Oosterbeek, 1997). But what about those who are still at university? What about their satisfaction with university life?

Our study is a follow-up to the work of Chan, Miller and Tcha (2005). Both papers concentrate on the happiness of university students, but whereas they analysed Australian university students, we gathered survey data from Finland. They used survey data from the University of Western Australia to obtain information on the most important factors influencing student satisfaction and happiness. We used a questionnaire similar to that of Chan et al. (2005) ${ }^{2}$ and collected survey data at the University of Jyväskylä, Finland. Chan et al. (2005) found the most important influences on students' levels of satisfaction are academic work, time management 
and relationships formed at university. They suggested extending the study to other countries, which is what we have done. We compare their results on the main factors affecting student satisfaction to those obtained among the present Finnish students. We also raise several issues in relation to the domains of satisfaction, in particular, in the course of analysing how happy university students are, how satisfied they are with university life and, finally, what determines their satisfaction as students. Understanding the main factors behind student satisfaction can be of value to educational policy planners, enabling better learning outcomes, cost-efficient public education and a highly motivated future workforce. We are interested in testing whether the same factors affecting Australian student's satisfaction (successful academic work, time management and relationships) also hold in another part of the globe. Do cultural or educational policy differences strongly affect students' preferences and attitudes, or are there common international factors making for student happiness?

\section{Most students are happy and satisfied - descriptive statistics}

The university of Jyväskylä is the second largest university in Finland (with 16,000 full-time students). It is public-funded with no student fees. The survey data was gathered among students attending the 'Basics of Economics' course at this university during autumn 2005. The survey was conducted in one lecture session in October. The number of completed questionnaires was 246 , implying that practically speaking nearly all students attending the course that day answered the survey. Our sample size is adequate for comparative purposes in this study. We assumed we would obtain largely similar results regarding student happiness factors as those found among the Australian students, as our survey questionnaire was based on the one used by Chan et al. (2005), with the exception that questions relating to overall happiness and religion were added. ${ }^{3}$ We believe that there are no large cultural differences between student bodies in Finland or in Australia, as both share western hemisphere values and culture. Nevertheless, as there are no tuition fees in Finland, contrary to the situation in Australia, we assumed that this difference might motivate the answers of Australian students more than would be case in Finland.

The gender distribution in the sample was pretty even, as $53.9 \%$ were female. Average age was 22 years and $70.1 \%$ of respondents were aged $19-22$ years. This is understandable, as the lecture course is a typical first- or second-year basic course, attracting a wide variety of different majors. $75.5 \%$ of respondents were either firstor second-year students. Although the students were rather young, 35.4\% had a part-time job. This could mean additional stress as such students are required to balance university and work, leaving them less time for leisure and extracurricular activities. 
Table 1: Basic descriptive characteristics of the respondents

\begin{tabular}{lcc}
\hline & C-M-T (2005) & Mangeloja and Hirvonen \\
\hline Sample size & 749 & 246 \\
Female, \% of total & 50.6 & 53.9 \\
Directly from high school, \% of total & 74.8 & 27.2 \\
Part-time employment, \% of total & 48.1 & 35.4 \\
Average working hours (of above), h & 11.2 & 10.5 \\
\hline
\end{tabular}

Note: C-M-T (2005) refers to the data obtained by Chan et al. (2005) for Australian university students.

On the other hand, part-time employment increases current financial stability and may give an advantage in the post-graduation employment market. The high proportion of respondents working part-time might also be connected to the fact that $31.0 \%$ of them come from the Jyväskylä region, and thus are already well connected with the surrounding economic environment. Table 1 presents the main characteristics of the respondents together with comparative data from the Australian study by Chan et al. (2005).

Finnish students seem to work a little less than their Australian counterparts. Also in the Chan et al.study, a clearly larger fraction of students are first-year students entering directly from high school. Only $27.2 \%$ of the Finnish students were direct entry from high school, compared to the $74.8 \%$ in Australia. If compulsory military service in Finland is taken into account, the proportion would increase to $45.5 \%$ in Finland, but would still be well below the Australian figure.

In the current study the largest group of respondents came from the School of Business and Economics, accounting for $36.4 \%$ of the total. $8.3 \%$ of the total were Economics majors. Other faculties were also well represented: $17.4 \%$ were from the Faculty of Information Technology, $16.6 \%$ from the Faculty of Humanities, $11.5 \%$ from the Faculty of Social Sciences and $4.1 \%$ from the Faculty of Mathematics and Sciences.

The main variable analysed here, as by Chan et al. (2005), is item SA1:'Overall, I am happy with my university life'. A five-category Likert Scale was used to score all the survey questions, the respondents being asked to nominate one of five categories: 1 = strongly agree, 2 = agree, $3=$ neutral, $4=$ disagree and $5=$ strongly disagree. Out of 246 responses, $22.8 \%$ of the students strongly agreed that their lives at the university were happy and $63.8 \%$ agreed that their lives at the university were happy, while none strongly disagreed, $4.9 \%$ disagreed and $8.5 \%$ were neutral. 
Table 2: Student satisfaction with university life: responses to statement 'Overall, I am happy with my university life'

\begin{tabular}{lcc}
\hline & C-M-T (2005) & Mangeloja and Hirvonen \\
\hline Strongly agree & 13.9 & 22.8 \\
Agree & 54.6 & 63.8 \\
Neutral & 23.1 & 8.5 \\
Disagree & 7.2 & 4.9 \\
Strongly disagree & 1.2 & 0.0 \\
\hline
\end{tabular}

Note: C-M-T (2005) refers to the data obtained by Chan et al. (2005) for Australian university students.

Compared to the Australian students, Finnish respondents seem to be more content with their life at university. The comparative results are presented in Table 2. In Finland, $86.6 \%$ of respondents are content (strongly agree or agree with the statement in item SA1) with their university life as against $68.5 \%$ in Australia. Only $4.9 \%$ of the Finnish students disagreed (disagree or strongly disagree), while the same figure was $8.4 \%$ in Australia. It should be noted that this small variation in our data, with most students being happy or neutral, weakens the estimation efficiency of our probit model. This may be one reason why we will obtain less significant coefficients for our regression than was obtained with the Australian data.

In order to assess the reliability of their responses to the above statement, students were also asked to respond to a similar statement:'Overall, university life has been good for me.'This satisfaction question (SA2) was placed towards the end of the questionnaire, whereas the first question (SA1) was placed towards the beginning of the questionnaire. Variable SA2 and SA1 were significantly correlated (although the correlation coefficient of 0.45 was lower than the 0.66 in Chan et al., 2005). This correlation coefficient is often termed the 'reliability' ratio.

The questionnaire used also included an item on overall happiness,'Overall, I am happy with my life.' Unlike the satisfaction with university life item, the happiness item measures general positive emotional mood (SA1 and SA2 are cognitive evaluations of a particular life domain). Also, the happiness item is thought to be global - that is, it includes all life-domains - while SA1 and SA2 are, as already said, domain-specific (for definitions see: Diener, 2005).

It should be noted that there were no missing answers to the happiness item: all the students answered it. According to Layard (2005) this is related to its validity: 
Table 3. Student happiness: Responses to statement:'Overall, I am happy with my life'

\begin{tabular}{lcc}
\hline & Frequency & Percent \\
\hline Strongly agree & 63 & 25.6 \\
Agree & 151 & 61.4 \\
Neutral & 24 & 9.8 \\
Disagree & 8 & 3.3 \\
Total & 246 & 100.0 \\
\hline
\end{tabular}

Note:This question was only asked of the Finnish students

'The scarcity of "Don't knows" (in social surveys to such items) shows that people do know how they feel, and recognise the validity of the question.'

Eighty-seven per cent of the students agreed with the statement 'Overall, I am happy with my life.' The percentage was only marginally higher than the Finnish Business and Policy Forum's survey's figure (where $85 \%$ of academics agreed with a similar statement). As expected, the happiness variable was highly and significantly correlated with both SA1 and SA2. The correlation coefficient was 0.489 with SA1.

In their study, Chan et al. (also Blanchflower and Oswald, 2004) found that university life satisfaction showed an inverted parabola with age, implying that the youngest and the oldest students recorded the highest level of satisfaction. In our data the same phenomenon is also present, as can be seen in Figure 1. Both the youngest

Figure 1: Satisfaction of students by age

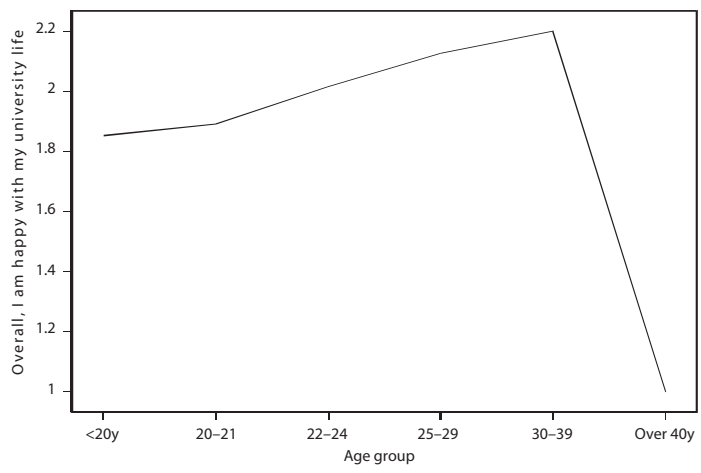


(below age 20) and oldest (age 40) students have the lowest values to item SA1, implying that they have the highest satisfaction with university life. The most discontented are the age group 25-29 years.

There seem to be no gender differences in happiness with university life in the Finnish data. SA1 variable has a clearly non-significant Mann-Whitney U-test statistic for gender differences, $(U=6936, p=0.267$, clearly implying no statistical difference). Similarly Chan et al. (2005) found that male and female respondents did not differ in their level of satisfaction in Australia. The same result has been found in several other studies (e.g. Frey and Stutzer, 2002).

The educational environment is assumed to influence students' happiness. $21.5 \%$ of the Finnish respondents strongly agreed that they were happy with their work environment while, at the other extreme, only $1.2 \%$ strongly disagreed with the statement. Moreover, the correlation coefficient between the satisfaction variable, SA1, and variable SS (I feel safe and secure) was 0.29 , with HWE (I am happy with my work environment) 0.07 , and with GC (the conditions of buildings and sports facilities are good) 0.15 . All were significant, except for'I am happy with my work environment' (HWE).

Students' lifestyles also seem likely to affect their happiness. Chan et al. write (p.26): 'As time is scarce, students must learn how to manage their lifestyle properly, and mishandling of time may lead to stress and unhappiness.' As with the Chan et al. survey, in the present survey the overwhelming majority of students reported 'neutral' or 'agree' for the following statements 'I can balance work and university activities well' (BWUAW), 'I can meet deadlines or goals in my university work' (MD) and 'I have sufficient recreational and entertainment time outside the home' (SRT). Moreover, the correlation matrix shows that all the three variables were positively and significantly correlated with the satisfaction variable (SA1). More detailed descriptive statistics of the main variables used is found in the appendix (Table 6).

\section{Determinants of student happiness - statistical analysis}

An ordered probit regression model was used to analyse the determinants of satisfaction with university life. We replicated the Chan et al. (2005) model, as the study setting was similar. They found that the significant explanatory variables responsible for higher levels of satisfaction with university life were satisfaction with academic work, good relationships formed, proper time management, good reputation of the university, income level and, to a lesser extent, satisfaction with the level of educational resources and the university environment. 
Table 4: Estimates of Ordered probit model of satisfaction with university life

\begin{tabular}{lcc}
\hline Variable & $\begin{array}{c}\text { Coefficient } \\
\text { (std.err) }\end{array}$ & $\begin{array}{c}\text { Wald } \\
\text { (significance) }\end{array}$ \\
\hline Age & $-0.558(0.425)$ & 1.727 \\
Gender & $-0.089(4.475)$ & 1.852 \\
Incomes (all) & $0.007(0.004)$ & 2.482 \\
Extracurricular activities & $-0.901(1.163)$ & 0.600 \\
Satisfaction with school work (HWM) & $0.448(2.008)$ & 0.050 \\
Satisfaction with resources and & $1.056(0.596)$ & $3.137 *$ \\
school environment & $2.517(1.200)$ & $4.401^{* *}$ \\
Relationships formed & $-0.169(0.633)$ & 0.071 \\
Time management & $1.387(1.248)$ & 1.235 \\
Health & $0.287(0.877)$ & 0.743 \\
University reputations & & \\
Pseudo R2, Cox and Snell & 0.852 & \\
Pearson goodness-of-fit, $\chi^{2}(50)$ & 16.136 & \\
Model fitting, $\chi^{2}(10)$ & $40.113 * * *$ & \\
\hline
\end{tabular}

Note: Dependent variable is SA1. Link function probit. $N=246$. Statistical significance is denoted by using ${ }^{* *},{ }^{* *},{ }^{*}$, which denote statistical significance at the $1 \%, 5 \%$ and $10 \%$ levels, respectively. Summary and goodness-of-fit statistics report degrees of freedom values in the parenthesis.

The results obtained with our data are shown in Table 4. The explanatory variables are identical to those used by Chan et al. (2005). Only two explanatory variables seem to be significant, one for good social relationships formed in the university (with p-value 0.036) and, to a lesser extent ( $p$-value 0.077 ), satisfaction with the level of resources and the university environment. For the Finnish students, time management, academic success, university reputation or incomes do not seem to contribute significantly to satisfaction with university life. Good social relationships seem to be a centrally important determinant of satisfaction, as a similar result was obtained in the Australian study.

Following the strategy used by Chan et al. (2005), we considered an alternative model in order that the sources of the school work and time management effects (composite variables created by aggregating the categorical responses to a number of components) might be better identified. While the school work and time management variables were not found significant in Table 4, we assumed that disaggregation of those variables might nevertheless reveal important information, 
Table 5: Ordered probit model of satisfaction with university life with sub-variables

\begin{tabular}{|c|c|c|}
\hline Variable & $\begin{array}{l}\text { Coefficient } \\
\text { (std.err) }\end{array}$ & $\begin{array}{c}\text { Wald } \\
\text { (significance) }\end{array}$ \\
\hline Age & $-0.052(0.118)$ & 0.193 \\
\hline Gender & $-1.012(0.839)$ & 1.154 \\
\hline Incomes (all) & $0.000(0.001)$ & 0.200 \\
\hline Extracurricular activities & $-1.579(0.845)$ & $3.496 *$ \\
\hline $\begin{array}{l}\text { Satisfaction with school work } \\
\text { (achieve standard, AAS) }\end{array}$ & $1.440(0.859)$ & $2.809 *$ \\
\hline $\begin{array}{l}\text { Satisfaction with school work } \\
\text { (happy with marks, HWM) }\end{array}$ & $-2.405(1.010)$ & $5.576^{* *}$ \\
\hline $\begin{array}{l}\text { Satisfaction with school work } \\
\text { (enjoy studying, ES) }\end{array}$ & $0.485(0.876)$ & 0.306 \\
\hline $\begin{array}{l}\text { Satisfaction with school work } \\
\text { (interesting work, DWTI) }\end{array}$ & $-0.642(0.518)$ & 1.538 \\
\hline $\begin{array}{l}\text { Satisfaction with school work } \\
\text { (cope with university work, COPE) }\end{array}$ & $0.175(0.608)$ & 0.083 \\
\hline $\begin{array}{l}\text { Satisfaction with resources and } \\
\text { school environment }\end{array}$ & $0.348(0.389)$ & 0.800 \\
\hline Relationships formed & $1.249(0.441)$ & $8.025 * * *$ \\
\hline Time management (work balance, BWUAW) & $0.802(0.491)$ & 2.665 \\
\hline Time management (meet deadlines, MD) & $0.372(0.470) 0.629$ & \\
\hline Time management (recreational time, SRT) & $-0.051(0.332)$ & 0.024 \\
\hline Health & $0.909(0.673)$ & 1.827 \\
\hline University reputations & $0.265(0.648)$ & 0.167 \\
\hline Pseudo R², Cox and Snell & 0.623 & \\
\hline Pearson goodness-of-fit, $\chi^{2}(83)$ & 128.919 & \\
\hline Model fitting, $\chi^{2}(16)$ & $33.159 * * *$ & \\
\hline
\end{tabular}

Note: Dependent variable is SA1. Link function probit. $\mathrm{N}=246$. Statistical significance is denoted by using ${ }^{* * *},{ }^{* *},{ }^{*}$, which denote statistical significance at the $1 \%, 5 \%$ and $10 \%$ levels, respectively. Summary and goodness-of-fit statistics report degrees of freedom values in the parenthesis. 
as in Chan et al. (2005). Thus, in this extended model, four different variables related to satisfaction with school work, and three related to time management, were added to the baseline model of Table 4. The other variables remain untouched. The estimation results are presented in Table 5.

Social relationships formed remained the main determinant of satisfaction with university life. Only one of the additional school work variables was found to be significant at the 5\% level of significance. The HWM variable represents the item 'I am happy with the marks I have achieved so far in university'. It should be noted that the sign of the coefficient is negative. Also, the AAS variable, which represents the item 'I achieve a standard in my work which I consider satisfactory', was significant (and positive), but only at the $10 \%$ level of significance. One theory (see e.g. Diener and Biswas-Diener, 2000: multiple discrepancy theory) that could explain such results is that those who achieve good grades feel satisfied with their work regardless of external validation. However, as in the case of AAS, their satisfaction is not independent of their own inner validation of study standards. When those are met, happiness ensues.

Additionally, extracurricular activities were now slightly significant, but only at the $10 \%$ level. Nevertheless, the coefficient was negative, indicating that more extracurricular activities either take time from studying or direct dissatisfied students to other activities, both of which may lower university life satisfaction. None of the three additional variables related to time management were significant in this alternative model.

In sum, students who had sufficient social relations were the happiest, which might not come as a big surprise. A far noteworthy finding is that the level of satisfaction among students who can balance work and activities well and can meet deadlines or goals, or succeed in their studies, does not differ significantly from that of students who cannot perform these functions.

\section{Conclusions - can we raise happiness by improving education?}

The first main issue dealt in this paper was to examine whether university students are happy or not. The answer to that question was a firm yes, in $87 \%$ of cases. Secondly, when asked whether they were happy with their university life, the students' answer again was a firm yes, in $86.6 \%$ of cases. Both figures correlate closely with the results from two stress and workload oriented studies, by Hiltunen and Väisänen (2002) and by Kallio (2002), conducted at the University of Jyväskylä. In Kallio's survey $92 \%$ of students out of 426 were satisfied with their studies at the university. In the survey by Hiltunen and Väisänen, only $20.4 \%$ out of 221 students felt either quite a lot of stress (15.4\%) or were extremely stressed (5\%) Not 
surprisingly, out of approximately 223 students $83 \%$ were satisfied with their lives and $87 \%$ with their studies in the Hiltunen and Väisänen's survey.

The present study also tried to identify which factors affect student satisfaction the most. They were relationships formed and, to a lesser extent, satisfaction with resources and the school environment, achieving personal standards and extracurricular activities. This implies that students who have sufficient social relations, good study resources and do not spend too much time on recreational activities and achieve their own goals, are the most satisfied with their time at the university. Rather surprisingly, neither time management, academic success, university reputation nor income seemed to contribute significantly to student happiness. Also, individual differences in age or gender had either little or no effect.

Public policy makers should take note of our result that personal success as a student does not seem to affect the satisfaction levels of students. Is the university system in Finland only producing an agreeable environment for social relationships, but not an education suited to a highly-qualified future workforce? Is there something wrong with the quality of university teaching, the grading system used or student incentives if students do not seem to care more about their grades? University policy makers may be able to use the results to further identify the major determinants of student satisfaction, and thus be better positioned to develop a learning environment that will enhance students' experience of university. Our results may also encourage students to organise themselves in order to attain their idea of 'the good life'. Our survey data was limited, but nevertheless able to reveal interesting points. Nevertheless, measurement of happiness and satisfaction remains a challenge. Future researchers should consider adopting a Likert Scale with more than the five categories used in our survey of satisfaction and happiness. This would increase the reliability of regressions. Moreover, rather than simply replicate the Chan et al. survey, attempts should be made to expand it, perhaps using focus groups to guide the construction of additional questions. This would certainly help advance and enrich the study of university students' happiness. 


\section{Appendix 1 Definition of variables}

\section{Dependent variables}

Satisfaction in University (SA1): The respondents' overall feelings towards their university life whereby the responses to the statement:'Overall, I am happy with my university life' were recorded in one of five categories:'strongly agree', 'agree', 'neutral', 'disagree' and 'strongly disagree'.

Table 6: Descriptive statistics of the main explanatory variables

Variable Values

Age: Student's age in years.

Mean $=22.2 ;$ Standard deviation $=3.4$

Gender: Dichotomous variable. Set to unity if the individual is female.

Males $=46.1 \%$; females $=53.9 \%$

Incomes (all): Continuous variable and measures the total amount of money a student receives from parents, the government and part-time jobs.

\section{Extracurricular activities:}

Dichotomous variable. Set to unity if the student partakes in university extracurricular activities.

Satisfaction with school work (achieve standard AAS): Categorical responses concerning school work for each student.

Satisfaction with school work (happy with marks HWM): Categorical responses concerning school work for each student.

\section{Satisfaction with school work} (enjoy studying ES): Categorical responses concerning school work for each student.

\section{Satisfaction with school work} (interesting work DWTI): Categorical responses concerning school work for each student.
Mean = 375.9 euros;

Standard deviation $=189.9$

Have extracurricular activities, yes $=50.4 \%$, no $=48.0 \%$

strongly agree $=15.5 \%$; agree $=64.1 \%$; neutral $=16.3 \%$; disagree/strongly disagree $=4.1 \%$ (combined)

strongly agree $=15.9 \%$; agree $=56.3 \%$; neutral $=24.1 \%$; disagree/strongly disagree $=3.7 \%$ (combined)

strongly agree $=17.5 \%$; agree $=64.2 \%$; neutral $=15.4 \%$; disagree/strongly disagree $=2.8 \%$ (combined)

strongly agree $=21.0 \%$; agree $=58.0 \%$; neutral $=14.4 \%$; disagree/strongly disagree $=6.6 \%$ (combined) 
Table 6: Descriptive statistics of the main explanatory variables (continued)

Variable
Satisfaction with school work
(cope with university work COPE):
Categorical responses concerning school
work for each student.
Satisfaction with resources and school
environment: This variable covered
whether students were happy with their
work environment, whether conditions of
buildings and sports facilities were good
and whether they felt safe and secure.

Relationships formed: The basis of this measure is the student's development of good relationships with school mates.

\section{Time management (work balance}

BWUAW): Categorical responses concerning whether a student can balance work and university activities well.

\section{Time management (meet deadlines}

MD): Categorical responses concerning whether a student can meet deadlines or goals in university work.

\section{Time management (recreational time}

SRT): Categorical responses concerning whether a student has sufficient recreational and entertainment time outside the home.

Health: Measures the student's self-reported good health conditions.

University reputations: This variable is created from information obtained on student's satisfaction with the reputation of the university they are studying at.

\section{Values}

strongly agree $=10.2 \%$; agree $=66.7 \%$; neutral $=18.7 \%$; disagree/strongly disagree $=4.5 \%$ (combined)

strongly agree $=15.0 \%$; agree $=54.1 \%$; neutral $=19.5 \%$; disagree $=9.8 \%$; strongly disagree $=1.6 \%$ strongly agree $=34.0 \%$; agree $=49.2 \%$; neutral $=9.0 \%$; disagree/strongly disagree $=7.7 \%$ (combined)

strongly agree $=12.6 \%$; agree $=32.2 \%$; neutral $=18.4 \%$; disagree $=31.0 \%$; strongly disagree $=5.7 \%$

strongly agree $=10.6 \%$; agree $=50.0 \%$; neutral $=24.0 \%$; disagree $=13.4 \%$; strongly disagree $=2.0 \%$

strongly agree $=23.7 \%$; agree $=46.9 \%$; neutral $=12.2 \%$; disagree $=14.7 \%$; strongly disagree $=2.4 \%$ strongly agree $=37.0 \%$; agree $=52.0 \%$; neutral $=5.7 \%$; disagree/strongly disagree $=5.3 \%$ (combined)

strongly agree $=26.0 \%$; agree $=66.8 \%$; neutral $=6.0 \%$; disagree/strongly disagree $=1.3 \%$ (combined) 


\section{References}

Argyle, M. (2002) The Psychology of Happiness, Routledge.

Blanchflower, D. G. and Oswald, A. J. (1997) The Rising Well-Being of the Young, NBER Working paper 6102.

Blanchflower, D.G. and Oswald, A. J. (2004) Well-Being over Time in Britain and the USA, Journal of Public Economics, 88(7-8), 1359-1386.

Chan, G., Miller, P. and Tcha, M. (2005) Happiness in University Education, International Review of Economics Education, 4, 1, 20-45

Clark, A and Oswald, A. (1996) Satisfaction and Comparison Income, Journal of Public Economics, 61, 359-381

Diener, E. (2005) Guidelines for National Indicators of Subjective Well-Being and III-Being, SINET, Fall, November 2005.

Diener, E. and Biswas-Diener, R. (2000) New Directions in Subjective Well-Being Research: The Cutting Edge, www.psych.uiuc.edu.

Diener, E., Suh, M., Lucas, R. and Smith, H. (1999) Subjective Well-Being:Three Decades of Progress, Psychological Bulletin, 125, 2, 276-302

Easterlin, R (2002) Happiness in Economics, The International Library of Critical Writings in Economics 142, Edward Elgar Publishing Limited, Cheltenham

Frey, B. and Stutzer, A. (2002) Happiness and Economics, Princeton University Press.

Hartog, J. and Oosterbeek, H. (1997) Health, Wealth, and Happiness: Why Pursue a Higher Education? University of Amsterdam, Department of Economics.

Hiltunen, S. and Väisänen, P. (2002) Yliopisto-opiskelu-stressaava elämänvaihe?:'Mitä kuuluu, yliopisto-opiskelija?' - kyselyn tuloksia, Masters thesis in Psychology, University of Jyväskylä, Spring 2002.

Hirvonen, T. and Mangeloja, E. (2005), You Will Find a Fortune, But Not the Fortune You Seek: On Income and Happiness, University of Jyväskylä, School of Business and Economics, Working Paper series, 295/2005.

Kahneman, D. and Krueger, A. (2006) Developments in the Measurement of Subjective Well-Being, Journal of Economic Perspectives, 20, 1, 3-24.

Kallio, E. (2002) The Misery and Happiness of Studying - Stress in University Studies, University of Jyväskylä. Institute for Educational Research, Occasional Papers 15.

Layard, R. (2005) Happiness: Lessons from a New Science, Penguin Press.

\section{Notes}

1 We are grateful for helpful comments and suggestions from two anonymous referees.

2 The permission to us the Happiness in Education Questionnaire was acquired from Grace Chan and Paul Miller.

3 Some other minor changes were also made, due to problems of translation. We did not use the data on religion, but are considering their use in future studies. 


\section{Contact details}

\section{Esa Mangeloja}

University of Jyväskylä,

School of Business and Economics,

P.O.Box 35,

FI-40014 University of Jyväskylä,

Finland

Email: eman@econ.jyu.fi

Tatu HirvonenUniversity of Jyväskylä, School of Business and Economics,

P.O.Box 35,

FI-40014 University of Jyväskylä,

Finland

Email: tathirvo@econ.jyu.fi 